\title{
Irrealis as verbal non-specificity in Koro (Oceanic)
}

\author{
JESSICA CLEARY-KEMP \\ University of California, Berkeley*
}

\section{Introduction}

Reality status is a verbal category that is typically understood as distinguishing between realized and unrealized, or hypothetical, states of affairs (see, e.g., Mithun 1999). ${ }^{1}$ However, significant variability has been observed in the function of so-called 'irrealis' morphemes across languages, and this has led some scholars, such as Bybee (1998) and De Haan (2012), to question the validity of irrealis as a cross-linguistic category. I will argue for an alternative hypothesis - namely that there exist two overlapping but notionally distinct categories that have both been labelled 'irrealis'. These categories are 'unreality' and 'temporal non-specificity'. I will give evidence from Koro, an Oceanic language of Papua New Guinea, for the existence of a coherent grammatical category encoding temporal non-specificity, and argue that the marker is a single morpheme with a stable meaning across uses. My thesis is that the apparent lack of a coherent 'irrealis' category, as bemoaned by those such as Bybee, is due to promiscuous descriptive use of the label, rather than due to the non-existence of such a category. A number of scholars have previously proposed that the irrealis construction in a given language has semantics of temporal non-specificity; what I would like to suggest here is that the 'temporal non-specificity' category is in fact notionally distinct from the 'unrealized' category, and that, despite their considerable overlap, they should be treated as separate domains in descriptive and typological work. Further cross-linguistic research on reality status is clearly necessary to confirm this hypothesis, but such research will be greatly aided by maintaining an analytical distinction between the two categories that have traditionally been referred to as 'irrealis'.

*The data presented here come from research generously funded by Endangered Languages Documentation Programme (ELDP) grant IGS0124 from the Hans Rausing Endangered Languages Project and an Oswalt Endangered Language Grant from the Survey of California and Other Indian Languages. I would like to thank my many consultants and friends in Koro village, especially John Kris and Mary Clara Hinduwan, Sylvia Pokisel, Stephen, Rose, and Rex Paura, Margaret Pohu, Rose Kewin, Michaela Kupwai, and Maria and Kris Pokisel. I would also like to thank Lev Michael, Peter Jenks, Tammy Stark, and the participants of BLS40 for their guidance and insightful comments. Any remaining errors are, of course, my own.

${ }^{1}$ The following abbreviations are used in this paper: ANDAT 'andative', COORD 'coordinator', DAT 'dative', DEF 'definite', DIST 'distal', DU 'dual', EXCL 'exclusive', IMPFV 'imperfective', INAN 'inanimate', INCL 'inclusive', IRR 'irrealis', NEG 'negation', NMLZR 'nominalizer', OBJ 'object', PERF 'perfect', PL 'plural', POSS 'possessive', PREP 'preposition', PROHIB 'prohibitive', PROSP 'prospective', PROX 'proximal', PRXMV 'proximative', REAL 'realis', SBJ 'subject', SG 'singular', SIMIL 'similative', SPEC 'specific'. Examples with a reference beginning 'Elicitation' were elicited, while all other examples are spontaneous utterances taken from recorded narratives, conversations, stimulus response tasks, etc. The following noteworthy orthographic conventions are used: $\langle\mathrm{br}\rangle$ represents $/ \mathrm{B} /,\langle\mathrm{j}\rangle$ represents $/ \mathrm{f} /$ (which is realized $/ \mathrm{d} /$ in younger people's speech), and $\langle\mathrm{r}\rangle$ represents $/ \mathrm{r} /$. 


\subsection{Definitions of reality status}

Traditional characterizations of reality status articulate a category that distinguishes between 'realized' or 'actual' and 'unrealized' or 'non-actual' situations (e.g., Mithun 1999:173). This approach emphasizes the truth-conditional semantics of propositions. Within such a framework, realis contexts include non-future tense, positive polarity, and indicative mood, while irrealis contexts include future tense and prospective aspect, conditionals (including counterfactuals), negative polarity, and jussive modalities. However, it has also been noted that in many languages other contexts can trigger the same marking found in irrealis contexts. For example, subjunctive in the Romance languages, which is used in many of the irrealis contexts outlined above, is also found in utterances where the proposition is not strongly asserted, either because it is in doubt, or because it is presupposed (Palmer 2001:11). Such systems suggest that 'non-assertion' is the core meaning of irrealis. This is related to the idea of 'uncertainty' - the less certain a speaker is about their assertion, the more likely irrealis is to occur (e.g., Timberlake 2007:328). As such, the contexts for occurrence of the irrealis include presupposition, doubt, and unrealized or hypothetical contexts such as future and counterfactual. This characterization of reality status focuses on the communicative function of irrealis. On the other hand, a number of languages use irrealis in what seems superficially to be a clearly realis context - past habitual. For example, the Papuan language Bargam uses irrealis marking in combination with past imperfective to mark backgrounded habitual events (Hepner 2006:134), and Givón (2001:359) notes that in many Austronesian languages the primary tenseaspect-mood distinction is between realis and irrealis, the latter category being used in habituals, among other contexts. This type of system has led to an alternative characterization of irrealis, namely that it encodes temporal non-specificity. This type of approach treats irrealis as analogous to 'non-specific' in the nominal domain, in that realis asserts or presupposes the existence of an event $\mathrm{E}$, whereas irrealis does not. Past habitual is non-specific in this sense because it quantifies over multiple past events, none of which is referred to directly. Expected contexts for irrealis marking under this approach include future tense and prospective aspect, conditionals (including counterfactuals), and past habituals.

Table 1 summarizes the contexts in which irrealis marking is expected, given each of these respective characterizations of its semantics. Contexts above the line are those in which the three types of semantic characterizations make the same predictions, while those below the line have different predictions for each definition of irrealis. It is clear from this table that contexts of negation, presupposition, uncertainty, and past habitual are the key environments in which to test the function of irrealis in a given language. In the following sections I will demonstrate that irrealis marking in Koro occurs in just those environments predicted by the 'temporal non-specificity' characterization.

\subsection{Criticisms of the notion of 'reality status'}

Given the cross-linguistic variation touched upon in the above discussion, a number of scholars have questioned the validity and usefulness of identifying an 'irrealis' category cross-linguistically. Bybee (1998), for example, argues that irrealis is not a universal gram-type (where gram-types are "crosslinguistically common focal points for grammatical expression" in a given conceptual domain (p.262)). She observes that we know of no language in which a single grammatical category expresses a distinction between real and unreal states of affairs, and she contrasts this with cate- 


\begin{tabular}{|l|l|l|l|}
\hline Semantics & $\begin{array}{l}\text { Unrealized marking } \\
\text { predicted }\end{array}$ & $\begin{array}{l}\text { Non-assertion } \\
\text { marking predicted }\end{array}$ & $\begin{array}{l}\text { Temporally } \\
\text { non-specific marking } \\
\text { predicted }\end{array}$ \\
\hline Jussive & Yes & Yes & Yes \\
Conditional & Yes & Yes \\
\hline Negation & Yes & No & No \\
Future, prospective & Yes & No & Yes \\
Presupposition & No & Yes & No \\
Uncertainty & No & Yes & No \\
Interrogative & No & Yes & No \\
Past habitual & No & No & Yes \\
\hline
\end{tabular}

Table 1: Comparison of contexts in which unrealized marking and temporally non-specific marking are predicted

gories such as perfective and imperfective aspect, which are grammatically encoded in language after language, and for which a stable core meaning can be posited cross-linguistically. However, Michael (to appear) has recently presented compelling evidence that Nanti, an Arawak language of Peru, does in fact have a binary inflectional category that distinguishes real from unreal states of affairs. Moreover, he shows that reality status is a stable grammatical category within the Kampan branch of Arawak, to which Nanti belongs. Given this counter-example, and the relative newness of scholarship on reality status, we might expect that other such neat reality status systems will be discovered as the concept is explored in more and more languages.

Bybee claims that languages fall into one of two categories in their treatment of the irrealis domain. The first type of language has a number of different morphemes, each of which covers only part of the conceptual domain of 'irrealis'. For example, Lake Miwok (Callaghan 1998) has separate morphemes for future, negation, purposive, and counterfactual, alongside a single morpheme that covers desire, intention and sometimes future and imperative. Bybee claims that in such languages there is no grammaticalized irrealis category; instead, there is a range of different morphemes with more specific meanings, such as 'desiderative' or 'optative'. This is a fair analysis of languages such as Lake Miwok, and I do not wish to propose that every language has a grammatically instantiated irrealis category. However, the existence of such languages does not disprove the cross-linguistic validity of 'irrealis' as a category. Many languages divide up other accepted gram-types into more fine-grained distinctions. For example, the category of 'past tense' in languages like Matses (Fleck 2007) and Luganda (Comrie 1985:93) is divided into finer semantic distinctions, such as recent, remote and distant, but this does not detract from the fact that "past tense' forms a coherent semantic domain for grammatical expression cross-linguistically. The difference between past tense and irrealis in this respect is that past tense is grammaticalized much more frequently in the world's languages than is irrealis. The claim here though is that this is a quantitative, rather than a qualitative, difference, and that the relative infrequency of its realization as a grammatical category is not strong evidence against the validity of irrealis as a cross-linguistic category.

In the second type of language that Bybee describes, a highly generalized morpheme occurs in most, but not all, of the contexts covered by the notion of 'irrealis'. Moreover, this generalized 
morpheme cooccurs with another, more specific, morpheme in each of its different uses. An example of this type of language is Caddo (Chafe 1995), in which the so-called 'irrealis' personal prefixes, when occurring alone, mark a polar interrogative. In all other uses they pair with another morpheme that specifies the type of irrealis meaning, such as negation, prohibition, obligation, conditional, simulative, infrequency, and surprise. Bybee analyzes so-called 'irrealis' morphemes in such languages as instead being a set of polysemous morphemes that each gets its specific meaning from the construction in which it occurs. This analysis likens the irrealis morpheme in such languages to morphemes like have in English. Aside from its lexical meaning of possession, have can denote obligation (I have to go to France) or perfect aspect (I have gone to France). These two uses of have do not reflect a core shared semantics, and in addition there are phonological and selectional differences between the two (for example, have selects an infinitival complement in one case and a past participle in the other). As such, it is clear that these two morphemes are separate morphemes that happen to have grammaticalized from the same source. Bybee argues that this is likewise the case for irrealis morphemes in languages of the type described here. I will argue, however, that Koro is an example of a language where this analysis does not fit. In contrast, I claim that the irrealis morpheme in Koro is indeed a single morpheme, and that it has a consistent, if abstract, core semantics across its uses.

The remainder of the paper is structured as follows. In $\S 2$ I first describe some relevant aspects of the grammar of Koro, then in $\S 3$ I outline the morpho-syntactic characteristics of reality status marking in Koro. In $\S 4$ I describe and exemplify each of the semantic contexts that trigger irrealis marking in Koro, and in $\S 5$ I explore the implications of the Koro data for a theory of reality status cross-linguistically. It should be noted that throughout this paper, although I refer to the morphemes in question as reality status morphemes, this is a matter of terminological convenience, and does not indicate an analytical claim. I urge the reader to keep in mind that these morphemes in Koro encode a distinction between temporal specificity and non-specificity, rather than a distinction between real and unreal events. One of my proposals is that the terminology in this domain should be made more precise, so as to distinguish between the different types of so-called reality status that have been identified. Since I know of no simple alternative, however, I retain the label 'irrealis' as a short-hand for the Koro category throughout this discussion.

\section{The Koro language and its speakers}

Koro is an Austronesian language, spoken by a few hundred people in Manus Province, off the north coast of the Papua New Guinea mainland. It is part of the little-studied Admiralties branch of the Oceanic sub-group. The dialect described here is spoken by some hundred or so people in the villages of Papitalai, Riu Riu, and Naringel, on Los Negros Island. Due mostly to pressure from Tok Pisin and English, intergenerational transmission is declining sharply in these villages, and all community members use Tok Pisin as their main language of everyday communication. The analysis presented here is based on data collected by the author during approximately seven months of fieldwork from 2009 to 2013, primarily conducted in Papitalai village.

Koro has strict SVO word order, and there is no case case-marking, other than in a small number of pronouns. The language is largely isolating, with aspect and mood categories primarily indicated by free morphemes. There is no grammaticalized tense, but reality status is obligatorily marked in verbal clauses. As shown in (1-2), morpheme $k$-indicates 'irrealis', and occurs between 
the subject and the verb, while realis is unmarked (see $\S 3$ below for further details).

(1) Ha you ku lisi Luwe.

ha you $\mathrm{k}-\mathrm{u}$ lisi Luwe

PROSP 1SG.SBJ IRR-1SG see Luwe

'I'll see Luwe.'

(2011-03-11-AH_AV-02_0257)

(2) I lisi Luwe.

i $\emptyset$ lisi Luwe

3SG REAL see Luwe

'He saw Luwe.'

(2011-03-11-AH_AV-02_0258)

Perfect aspect and negation morphemes also occur between the subject and the verb. As shown in (3), perfect aspect is marked by morpheme $k-\ldots-n i$, while negation is marked by preverbal $t a$ combined with clause-final $p w i$, as in (4).

(3) I pihin a, i kini hekohe timou ndramat ta lohanum.

i pihin a i k-i-ni hekohe timou ndramat ta lohanum 3SG woman DIST 3SG PERF-3SG-PERF hide one:PERSON person LOC inside.house

'That woman, she has hidden a man inside her house.'（v2012-08-02-CB-04_0231)

(4) I ta jan pwi.

i ta jan $\emptyset \quad$ pwi

3SG NEG eat 3INAN.OBJ NEG

'He didn't eat it.'

(2011-03-09-AH_AV-01_0078)

Reality status, perfect aspect, and negation are in complementary distribution, and only one of the three categories can occur in a simplex clause. There is also a pre-verbal aspectual slot, which houses prospective marker $(h) a$, and an additional slot immediately before reality status, in which proximative $p$ - can occur. Prospective is used with future temporal reference where the speaker has a high degree of certainty about the eventuality occurring, as illustrated in (5). Proximative, on the other hand, is used for imminent states of affairs regardless of certainty, and often has a desiderative implicature, as shown in (6). Both require irrealis $k$ - to cooccur (as discussed further in $\S 4$ below).

(5) Ha i ki los me pwan.

ha $\mathrm{i} \quad \mathrm{k}-\mathrm{i} \quad$ los me pwan

PROSP 3SG IRR-3SG fall come down

'He will fall down.'

(Elicitation-2013-07-30-AD_CA_0122)

(6) I pi ki los me pwan.

i p-i k-i los me pwan

3SG PRXMV-3SG IRR-3SG fall come down

'He is about to fall down $\sim$ He wants to fall down.'(Elicitation-2013-07-30-AD_CA_0121)

Table 2 shows the positional slots in the Koro verbal clause (where 'AM' stands for 'aspectmodality'). 


\begin{tabular}{|c|c|c|c|c|c|c|}
\hline AM slot 1 & Subject & AM slot 2 & AM slc & & Verb & Clause-final \\
\hline$(h) a \quad$ PROSP & & $p-\quad$ PRXMV & $\begin{array}{l}k- \\
k-\ldots-n \\
t a\end{array}$ & $\begin{array}{l}\text { IRR } \\
\text { PERF } \\
\text { NEG }\end{array}$ & & pwi NEG \\
\hline
\end{tabular}

Table 2: Surface positional slots in the Koro clause

\section{Morpho-syntax of reality status in Koro}

As noted above, irrealis in Koro is marked by pre-verbal particle $k$-, which occurs immediately before the verb. This is illustrated again in (7), where the irrealis morpheme $k u$ occurs between subject you 'first person singular' and verb piri 'take (a person)'.

(7) You ku piri nambrulu.

you $\mathrm{k}-\mathrm{u}$ piri nambrulu- $\emptyset$

1SG.SBJ IRR-1SG take:person spouse-1SG.POSS

'I'm going to take a wife.'

(2011-03-07-AH_AV-03_0092)

Realis, on the other hand, is indicated by the absence of an overt marker between the subject and verb, as in (8). Here there is no marker between subject yourun 'first person plural exclusive' and verb $l a$ 'walk'. The utterance is interpreted as realis, and by default, past tense.

(8) Yourun la le hou a.

yourun $\emptyset$ la le hou a

1PL.EXCL REAL walk go.to bush DIST

'We walked to the bush.'

(v2012-07-21-AD_BZ-02_0029)

Irrealis $k$ - inflects to agree with the subject of the clause. However, there is massive syncretism in the irrealis paradigm. Koro personal pronouns distinguish three persons, as well as singular, dual and plural number, and inclusive and exclusive in the first person. In the irrealis inflections on the other hand, three persons are distinguished in the singular, but there is just a single suffix for all non-singular persons. Note that with the first person singular subject in (7) above irrealis has the form $k u$, while with third person singular subject $i$ in (9) it becomes $k i$.

(9) I ki tuweni kaikai.

i k-i tuwe-ni kaikai

3SG IRR-3SG cook-SPEC.OBJ food

'She will cook the food.'

(2011-04-23-AA-02_0038)

In contrast, irrealis is realized invariantly as $k a$ with both second person dual aru in (10) and first person plural exclusive yourun in (11). It does not inflect for person, nor are there different forms for dual and plural number. 
(10) Aru ka la hou!

aru k-a la hou

2DU IRR-NON.SG go:ANDAT bush

'You two go to the bush!'

(v2012-07-21-AD_BZ-02_0014)

(11) Yourun ka la mwa yourun ka lisi.

yourun k-a la mwa yourun $\mathrm{k}-\mathrm{a} \quad$ lisi $\emptyset$

1PL.EXCL IRR-NON.SG go COORD 1PL.EXCL IRR-NON.SG See 3INAN.OBJ

'We'll go and we'll watch it.'

(v2012-07-21-AD_BZ-02_0067)

Suppletive irrealis form $a$ occurs in second person singular, as shown in (12).

(12) Au a la hou liye, a la kah pamei e warah!

au a la hou liye a la kah pamei e

2SG 2SG:IRR go:ANDAT bush again 2SG:IRR go:ANDAT look.for betelnut COORD

warah

mustard

'You, go to the bush again and look for betelnut and mustard!'

(2011-03-08-AH_AV-01_0051)

Often the second person singular pronoun $a u$ is omitted in such constructions, as in (13).

(13) A le pelingan, a nak pamei sarah!

a le pelingan a nak pamei sa-rah

2SG:IRR go up 2SG:IRR climb betelnut stand-DIST

'Go up there and climb the betelnut that's standing over there!'

(2011-03-08-AH_AV-01_0080)

Table 3 shows the full Koro irrealis paradigm.

\begin{tabular}{|l|c|c|c|}
\hline & $1^{\text {st }}$ person & $2^{\text {nd }}$ person & $3^{\text {rd }}$ person \\
\hline SINGULAR & $k-u$ & $a$ & $k-i$ \\
\hline NON-SINGULAR & \multicolumn{3}{|c|}{$k-a$} \\
\hline
\end{tabular}

Table 3: Koro irrealis forms

\section{Distribution of irrealis in Koro}

Here I outline the range of functions that irrealis-marked clauses fulfill in Koro discourse. These divide into contexts in which irrealis $k$ - can or must be the only instantiation of irrealis in the construction, and those in which $k$ - obligatorily combines with another, more specific, irrealis morpheme. I discuss each of these contexts in turn. Past habitual is discussed separately. Finally, I present a number of contexts that are marked as irrealis in other languages, but are realis in Koro. Table 4 summarizes the contexts that trigger irrealis marking in Koro. 


\begin{tabular}{|l|l|l|}
\hline Semantics & Triggers irrealis in Koro & Additional morpheme \\
\hline Future & Yes & ha optional \\
Prospective & Yes & ha optional (very rare) \\
Jussive modalities & Yes & none \\
Other deontic modalities & Yes & mas, kara optional with necessity \\
Purposive complement & Yes & piri optional \\
Desiderative complement & Yes & none \\
Conditionals & Yes & lengeri, tehene optional on protasis \\
Proximative & Yes & p- \\
Prohibitive & Yes & mbrwa \\
'In case' & Yes & mala $(p w i)$ \\
Past habitual & Optional & none \\
\hline Negation & No & NA \\
Uncertainty/inference & No & NA \\
Frustrative & No & NA \\
Interrogatives & No & NA \\
\hline
\end{tabular}

Table 4: Distribution of irrealis marking in Koro

\subsection{Irrealis contexts that do not require an additional specifying morpheme}

Future tense, prospective aspect, jussive (or speaker-oriented) modalities, other deontic modalities, purposive adjuncts, and desiderative complements require irrealis $k$ - to occur in Koro. All of these meanings are frequently realized without the addition of a more specific morpheme, and jussive modalities and desiderative complements do not allow any additional irrealis morpheme to occur. As such, the meaning of an irrealis clause is often only discernible in context. All translations in the following examples are those given by native speakers in the context of the ongoing discourse. Elicited examples are typically speakers' translations into Koro of sentences I presented in English.

The utterances in (14-15) have future temporal reference. The clause in (14) is marked only by irrealis $k u$, whereas that in (15) is marked additionally by prospective aspect marker $h a$. The difference between future referring clauses with and without ha is not entirely clear, but it appears that those marked with ha may indicate greater certainty on the part of the speaker than those without. The exact semantic contribution of ha requires further research.

(14) Mwah you ku me nam niu.

mwah you k-u me namw niu next.day 1SG.SBJ IRR-1SG come scrape coconut

'Tomorrow I'll come and scrape coconut.'

(Elicitation-2013-07-18-AD_0003)

(15) Mwah, ha you ku senisim au.

mwah ha you $\mathrm{k}-\mathrm{u}$ senisim au next.day PROSP 1SG.SBJ IRR-1SG change 2SG

'Tomorrow, I will change you.'

(2011-03-07-AH_AV-03_0056) 
Irrealis $k$ - and prospective $h a$ also occur in relative future, alternatively termed prospective aspect (although $h a$ occurs only rarely in these contexts). In prospective aspect, the reference time is prior to the time of utterance, but the time of the event is projected to be after the reference time. In other words, it is the 'future in the past'. The utterance in (16), for example, is from a first person narrative in which the speaker is recounting events that actually occurred in the past. She uses irrealis $\mathrm{ka}$ to indicate the subjects' intention at the time to go and look for betelnut. In (17), on the other hand, irrealis marking occurs in the complement clause ha i ki me 'he would come'. The reference time here is the time at which Rex informed the speaker, and use of irrealis indicates that Rex's coming was anticipated to occur after that time. (The final clause indicates this did not in fact eventuate.)

(16) Yourun ka la kah pamei.

yourun k-a la kah pamei

1PL.EXCL IRR-NON.SG go:ANDAT look.for betelnut

'We were going to go and look for betelnut.'

(v2012-08-02-CB-01_0042)

(17) Rex i popohar jua munuwe ha i ki me, tapwah i ta me pwi.

Rex i $\emptyset$ popoharjua munuwe ha $\mathrm{i} k-\mathrm{i}$ me tapwah $\mathrm{i}$ ta me Rex 3SG REAL inform 1SG prev.day PROSP 3SG IRR-3SG come but 3SG NEG come pwi

NEG

'Rex told me yesterday he would come, but he didn't come.'

(Elicitation-2012-07-12-AD_BZ_0132)

Another context in which irrealis $k$ - is obligatory is with jussive modalities, including imperative (18), hortative (19), and optative (20). The optative clause in (20) ki ru (literally 'let it stay') is used here as a polite imperative 'leave it!'

(18) A rei mweh!

a re-i mweh

2SG:IRR hit-SPEC:OBJ dog

'Hit the dog!'

(Elicitation-2011-03-09-AH_AV_0024)

(19) To ka la so ni!

to $\quad \mathrm{k}-\mathrm{a} \quad$ la so ni

1PL.INCL.SBJ IRR-NON.SG go spear fish

'Let's go and spear fish!'

(2011-03-08-AH_AV-01_0107)

(20) Ndwal a ki mekek. Ki ru!

ndwal a $\mathrm{k}-\mathrm{i} \quad$ mekek k-i ru

canoe DIST IRR-3SG flimsy IRR-3SG stay

'The canoe will be too flimsy. Leave it (literally: let it stay)!'

(2011-03-21-AH_AV-02_0038) 
All of the jussive modalities are expressed by the irrealis, with no additional specifying morpheme.

Deontic modalities of weak and strong necessity also require irrealis $k$-, with or without another specifying morpheme. For example, in (21), deontic 'should' is encoded solely by irrealis marking, while in (22) irrealis marking combines with distal demonstrative kara to encode a similar meaning.

(21) I pwai le he kei, kei le ndramat piri pwan, rang i ki ru, kei ta chinal, ki mul le pilingan.

i $\emptyset$ pwa-i le he kei kei le ndramat piri pwan rang $\mathrm{i}$ 3SG REAL say-SPEC.OBJ go.to DAT tree tree go.to man of ground day $3 \mathrm{SG}$

k-i ru kei ta chinal k-i mul le pilingan

IRR-3SG stay tree POSS devil IRR-3SG return go.to sky

'He said to the tree, if it was a man from the earth, it should stay in the day, if it was a devil's tree it should go back to the sky.'

(2011-03-07-AH_AV-03_0106-09)

(22) Kara a chim rais le taun le cha mbrunen ndohin.

kara a chim rais le taun le chah mbrune-n ndohin

DIST 2SG:IRR buy rice go.to town because price-3SG.POSS small

'You should buy rice in town because it's cheaper.'

(Elicitation-2011-03-22-AH_AV_0094)

Strong necessity can also be encoded by either irrealis alone, as in (23), or by irrealis in combination with control verb mas 'must', as in (24).

(23) Aruwar to ka inei mangas cholan.

aruwar to $\quad \mathrm{k}-\mathrm{a} \quad$ inei mangas cholan

now 1PL.INCL.SBJ IRR-NON.SG make work plenty

'Now we must do a lot of work.'

(Elicitation-2012-07-12-AD_BZ_0160)

(24) You mas you ku la kah yeniyan.

you $\emptyset$ mas you k-u la kah yeniyan

1SG.SBJ REAL must 1SG.SBJ IRR-1SG go:ANDAT look.for food

'I must go and find some food.'

(2011-03-22-AH_AV-03_0015)

Purposive and desiderative constituents also require irrealis marking. Purposive adjuncts either take irrealis marking by itself, as in (25), or they are introduced by preposition piri 'for, of', as in (26). There is no clear semantic distinction between purposives with and without piri. (Note that the events marked as irrealis in (26) have actually occurred at the time of utterance, and are therefore 'realized' events in the strictest understanding of the term.)

(25) You ku ruwi au a la leti a senisim au mwa...

you k-u ruwi au a la le=ti a senisim au 1SG.SBJ IRR-1SG put 2SG 2SG:IRR go:ANDAT PROX=stay 2SG:IRR change 2SG mwa

COORD 
'I will take you so you can go and change yourself, and...'

(2011-03-07-AH_AV-03_0060)

(26) Au senisim au piri a me mwa a piri jua.

au $\emptyset$ senisim au piri a me mwa a piri jua

2SG REAL change $2 \mathrm{SG}$ for 2SG:IRR come COORD 2SG:IRR get.person 1SG.OBJ

'You changed yourself so that you could come and marry me.'

(2011-03-08-AH_AV-01_0182)

Complements of desiderative verbs such as lengi, laikim 'want, like', and mbrwere- 'not want, dislike' are marked as irrealis, as in (27-28). The complement is optionally introduced by the preposition lengeri 'like'. 2

(27) i $\emptyset$ laikim lengeri ni mwatih k-i ru polo ndwal 3SG REAL want like fish every IRR-3SG stay top canoe

'He wanted all the fish to stay in the canoe.' (2011-03-08-AH_AV-01_0116)

(28) You mbrwere ni ki lus.

you $\emptyset$ mbrwere- $\emptyset$ ni $\mathrm{k}-\mathrm{i}$ lus

1SG.SBJ REAL not.want-1SG:POSS fish IRR-3SG be.lost

'I don't want the fish to disappear.'

(2011-03-08-AH_AV-01_0112)

In the above examples the desired (or undesired) event is after the reference time, and therefore this usage falls within an analysis of irrealis as a marker of prospective aspect. When the desiderative complement does not have future temporal reference, however, it surfaces instead as a nominalized VP. This is shown in (29-30), where the nominal complements instantiate ongoing or iterated activities with past or present temporal reference.

(29) You lengi mesenga ndap.

you $\emptyset$ lengi meseng-a ndap

1SG.SBJ REAL like make-NMLZR basket

'I like making baskets.'

(Elicitation-2012-07-11-AD_BZ_0085)

(30) I ta mbrweren kaniya epi.

i ta mbrwere-n kan-iya epi

3SG IMPFV not.want-3SG.POSS eat-NMLZR sago

'He never wants to eat sago.'

(Elicitation-2013-07-31-AD_CA_0103)

Certain verbs, however, cannot be nominalized. These include all path and locative verbs. When such a verb occurs in the complement to a verb of desire, it is marked as irrealis, whether it has future temporal reference or not. This is illustrated in (31), where the activity of going to town is understood to have occurred, and continues to occur, every day. Since path verb le 'go to' cannot be nominalized, it instead occurs in an irrealis-marked clausal complement.

${ }^{2}$ The root mbrwere- is one of a small class of predicative elements that behave morphologically like inalienable nouns, taking a possessive suffix to agree with the subject of the clause. The other such roots are mucho- 'be full' and tana'know'. 
(31) You lengi you ku le taun le rang mamonein.

you $\emptyset$ lengi you $\mathrm{k}-\mathrm{u}$ le taun le rang mamonein

1SG.SBJ REAL like 1SG.SBJ IRR-1SG go.to town PREP day every

'I like to go to town every day.'

(Elicitation-2012-07-11-AD_BZ-0096)

This shows that the function of irrealis in desiderative complements cannot be reduced to prospective aspect, since not all occurrences fit the criteria for prospective aspect.

Conditionals, including hypothetical and counterfactual constructions, are another context in which irrealis marking is obligatory. In Koro, the protasis of a conditional is typically introduced with tehene 'thus' or lengeri 'like', although there is occasionally no overt marking of the protasis (see (33) below). In a hypothetical conditional, only the apodosis must be marked for irrealis. This is demonstrated in (32), where the protasis lengeri i kini koh niu 'if she has gathered coconuts' is marked for perfect aspect, and the apodosis ha i ki ru mesenge ndrelike 'she will be making oil' is marked as irrealis.

(32) Lengeri i kini koh niu, ha i ki ru mesenge ndrelike.

lengeri i k-i-ni koh niu ha i $\mathrm{k}-\mathrm{i}$ ru mesenge ndrelike

like 3SG PERF-3SG-PERF gather coconut PROSP 3SG IRR-3SG stay make oil

'If she has gathered coconuts, she will be making oil.' (Elicitation-2012-08-08-BZ_0048)

In hypothetical conditionals such as this, the speaker is not committed to the truth of the proposition in the protasis, but nor are they committed to its falsehood. Counterfactuals, on the other hand, entail that the proposition in the protasis is false. As such, both the protasis and the apodosis of a counterfactual conditional are marked for irrealis. For instance, the utterance in (33) entails that the subject is not here now, and the protasis $i$ ki ru rangeh 'if she were here now' is marked as irrealis. The apodosis is not irrealis-marked in this example because it has a non-verbal predicate tehene ke jua 'like me', which cannot host any aspect or mood marking.

I ki ru rangeh e i tehene ke jua kepi e.

i k-i ru rangehe $\mathrm{i}$ tehen-e ke jua kepi e 3SG IRR-3SG Stay:IRR nOw COORD 3SG SIMIL-PROX DAT 1SG only PROX

'If she were still here she would be just like me.' (2011-04-23-AA-02_0180-81)

In contrast, the utterance in (34) has a non-verbal protasis and a verbal apodosis, and here the apodosis takes irrealis marking.

(34) Munuwe tehene lengin, you ku ru kor.

munuwe tehen-e lengin you k-u ru kor

yesterday SIMIL-PROX rain 1SG.SBJ IRR-1SG stay:IRR place

'If it had rained yesterday, I would have stayed home.'

(Elicitation-2011-03-31-AH_AV_0002)

In summary, the apodosis of a hypothetical conditional is marked as irrealis, while the protasis, which the speaker neither asserts to be true nor false, is not. In contrast, the apodosis and protasis of a counterfactual, both of which the speaker asserts to be false, are both marked as irrealis. 


\subsection{Irrealis contexts that require an additional specifying morpheme}

I now move on to discuss the contexts in which irrealis $k$-obligatorily combines with another, more specific, morpheme. These contexts are proximative aspect, prohibitives, and precautionary adjuncts.

Proximative is a grammatical aspect that indicates that the eventuality of the predicate is imminent (Heine 2002:90). In Koro this aspect is indicated by particle $p$-, which follows the same inflectional paradigm as irrealis $k-{ }^{3}$ For example, use of proximative in (35) indicates that the canoe is on the brink of floating away.

(35) Ndwal pi ki pit le mahun.

ndwal p-i $\quad \mathrm{k}-\mathrm{i} \quad$ pit le mahun

canoe PRXMV-3SG IRR-3SG float go far

'The canoe is about to float away.'

(Elicitation-2012-08-08-BZ)

Proximative aspect can occur with both volitional and non-volitional subjects, and with volitional subjects it typically has a desiderative implicature, as in (36-37).

(36) E pi ki la lisi. Pwi, ta tu pwi.

e $\quad \mathrm{p}-\mathrm{i} \quad \mathrm{k}-\mathrm{i} \quad$ la $\quad$ lisi $\emptyset$ pwi ta tu pwi

COORD PRXMV-3SG IRR-3SG go:ANDAT see 3INAN.OBJ NEG NEG stay NEG

'And she wanted to go and see it, but no, it wasn't there.' (2011-03-09-AH_AV-01_0071)

(37) Youru noh. Youru pa ka chong le hou.

youru $\emptyset$ noh youru $\quad \mathrm{p}-\mathrm{a} \quad \mathrm{k}-\mathrm{a} \quad$ chong le hou

1DU.EXCL REAL be.afraid 1DU.EXCL PRXMV-NON.SG IRR-NON.SG enter go.to bush

'We were afraid, we wanted to go into the bush.'（v2012-07-21-AD_BZ-03_0015)

To express proximative aspect, both proximative $p$ - and irrealis $k$ - are required. As shown in (38), proximative cannot occur without irrealis marking.

(38) You $\mathrm{pu} *(\mathrm{ku})$ metir.

you $\mathrm{p}-\mathrm{u} \quad \mathrm{k}-\mathrm{u} \quad$ metir

1SG.SBJ PRXMV-1SG IRR-1SG sleep

'I want to sleep.'

(Elicitation-2011-03-21-AH_AV_0089-91)

Like the proximative, prohibitive mbrwa also obligatorily occurs with irrealis. It is a modality indicating prohibition or admonition, as in (39) or negative optative, as in (40).

(39) Mbrwa a la hou!

${ }^{3}$ Older speakers, however, often realize this morpheme as $p a$, regardless of the person or number of the subject. It is likely that the proximative particle grammaticalized from lexical verb $p w a$ 'say', and that the inflection observed in younger speakers' discourse is a result of vowel harmony, influenced by the vowel of the following irrealis morpheme. I nonetheless treat it as morphological inflection here, since my primary consultants consider the invariant $p a$ form incorrect. 
mbrwa a la hou

PROHIB 2SG:IRR go-ANDAT bush

'Don't go to the bush!'

(Elicitation-2011-03-21-AH_AV_0088)

(40) Mbrwa awei mandan ki me!

mbrwa awei mandan k-i me

PROHIB wave big IRR-3SG come

'Let a big wave not come!'

(Elicitation-2011-03-21-AH_AV_0087)

Finally, precautionary adjuncts, expressing a semantics of 'in case' or 'lest', are also obligatorily marked as irrealis. The precautionary semantics is encoded by the complementizer mala (pwi). The pwi (which is a negation particle) appears to be optional in this construction, and its inclusion or omission does not seem to affect the semantics of the construction. The proposition expressed in the mala pwi clause can be either a desired or an undesired event, as illustrated in (41-42) respectively.

(41) You letu sirah mala pwi to ko kah karahat.

you le $=$ tu $\quad \operatorname{sirah} \emptyset \quad$ mala pwi to $\quad \mathrm{k}-\mathrm{a} \quad \mathrm{kah}$ 1SG.SBJ PROX=stay carry 3INAN.OBJ in.case 1PL.INCL.SBJ IRR-NON.SG search.for

karahat

mud.crab

'I'm bringing it (a bag) in case we find any mud crabs.'(Elicitation-2012-07-23-BZ_0078)

(42) You chongani life jacket mala pwi ndwal ki lol.

you $\quad \emptyset \quad$ chongani life jacket mala pwi ndwal k-i lol

1SG.SBJ REAL wear life.jacket in.case canoe IRR-3SG sink

'I put on the life-jacket in case the canoe sinks.' (Elicitation-2012-07-23-BZ_0079)

The mala pwi clause can also express an aversive meaning, 'lest'. In (43), for example, the proposition $u$ ka rei au is an undesired event that the event of the main clause is intended to avert.

(43) You ku lop mala u ka rei au.

you k-u lop mala $\mathrm{u}$ k-a re-i au

1SG.SBJ IRR-1SG hide in.case 3PL.SBJ IRR-NON.SG strike-SPEC.OBJ 2SG

'I'll hide, lest they beat you.'

(Elicitation-2012-06-29-AV_0037)

As can be seen from the above examples, the mala pwi clause in all these uses takes irrealis marking.

\subsection{Past habitual}

For the most part, the contexts for irrealis marking described above are fairly unsurprising, and do not provide strong evidence against an interpretation of Koro irrealis as encoding 'unrealized' events. I discuss past habitual separately here because, given the 'unrealized' characterization 
of irrealis, it is an unexpected context in which to find irrealis marking. Past habitual events are, after all, a prototypical instance of 'realized' events. They are asserted to have actually occurred a number of times in the past, and it is therefore surprising that they should trigger irrealis marking. Nonetheless, as noted in $\S 1.1$ above, irrealis marking of past habituals is reported for a number of languages, and past habitual is a predicted context for irrealis marking when irrealis is understood as a category encoding temporal non-specificity. In Koro, past habitual events are optionally marked as irrealis. The typical way of expressing past habitual events is in a realis serial verb construction, with one of the verbs $r u$ or $r i$ 'stay, be located'. This is illustrated in (44), which is not marked for irrealis, but expresses a past habitual meaning.

(44) Hamu, tino i ri tuwe karahat.

hamu tino i $\emptyset$ ri tuwe karahat

before mother:1SG.POSS 3SG REAL stay cook mud.crab

'Before, my mother used to cook mud crab.'（Elicitation-2012-08-06-AD_BZ_0086)

The same serial verb construction can also express other imperfective aspects, as illustrated in (45). Here the interpretation is past continuous, rather than habitual. Whether this type of serial verb construction is interpreted as habitual or continuous is largely dependent on context.

(45) Munuwe i ri singe chalau.

munuwe i $\emptyset$ ri singe chalau

day.before 3SG REAL stay wash laplap

'Yesterday s/he was washing clothes.'

(Elicitation-2011-03-31-AH_AV_0062)

In narratives habitual aspect is often not indicated by the imperfective aspect construction shown above, but is instead indicated by irrealis $k-$, as in (46).

a. Ol taim i ki la ki ri pondrawat he rutun le pohaleng.

ol taim i k-i la k-i ri pondrawat he rutun le

DEF.PL time 3SG IRR-3SG go IRR-3SG stay:IRR play DAT 3PL go.to

pohaleng.

beach

'All the time he would go and he would be playing with them on the beach.'

b. I la ki la mwa tehene...

i la k-i la mwa tehen-e

3SG go IRR-3SG go COORD SIMIL-PROX

'It went on and on and...'

(2011-04-23-AA-02_0216-0217)

The habitual semantics of this construction is indicated by use of the adverbial ol taim 'all the time', and by the following clause $i$ la ki la 'it went on and on'. A variant of this clause almost always follows a habitual description, and can be repeated iconically to indicate duration.

Another example of a habitual construction is in (47). Here the speaker is telling a story based on a series of pictures provided to her. ${ }^{4}$ She is describing the typical daily activities of the subjects

\footnotetext{
${ }^{4}$ The pictures were part of San Roque et al's (2012) narrative problem solving task.
} 
in the pictures. After setting up this background, she then relates a particular climactic event that occurred only once in the narrative. In relating this individual event, of the man hitting his wife, she switches from irrealis marking to unmarked realis.

a. U ndramat e u ka leti jin ndran,

u ndramat $=\mathrm{e}$ u $\mathrm{k}-\mathrm{a} \quad \mathrm{le}=\mathrm{ti} \quad$ jin ndran

3PL man=PROX 3PL.SBJ IRR-NON.SG go.to=stay drink fresh.water

'These men would go out drinking.'

b. hengorou piri keheya pihin a tirah.

hengorou piri kah-iya pihin=a ti=rah.

thought of look.for-NMLZR woman=DIST stay=DIST

'and they would think about looking for women.'

c. I ki mul le kor i ki le tah nambrulun.

i k-i mul le kor i k-i le tah nambrulu-n

3SG IRR-3SG return go.to village 3SG IRR-3SG go.to strike spouse-3SG.POSS

'He would return to the village and he would go and hit his wife.'

d. I la i la i la, piri tih a i rei nambrulun.

i la i la i la piri tih=a i $\emptyset$ re-i nambrulu-n $3 \mathrm{SG}$ go $3 \mathrm{SG}$ go $3 \mathrm{SG}$ go time one=DIST $3 \mathrm{SG}$ REAL strike-SPEC.OBJ spouse-3SG.POSS

'This went on and on until one time he hit his wife.' 0391-94)

(2011-04-07-AH_AV-03_

As is clear from these examples, irrealis marking is a common device used to relate events in habitual aspect. Its use in this context does not fit with a characterizatin of irrealis as marking 'unrealized' events. In $\S 5$ I will discuss further how habitual and related uses can be explained by invoking a 'temporally non-specific' semantics for irrealis aspect.

\subsection{Contexts that do not trigger irrealis marking}

In this section I describe a number of contexts that are treated as irrealis in certain other languages, but do not trigger irrealis marking in Koro. These contexts include negative polarity, uncertainty, frustrative, and interrogative mood.

Events under the scope of negation are by definition unrealized, and would therefore be expected to trigger irrealis marking. In Koro, however, negative polarity does not trigger irrealis marking. As shown in (48), negation in verbal clauses is instead indicated by pre-verbal particle $t a$, in combination with clause-final $p w i$.

(48) You ta tuweni ni pwi.

you ta tuwe-ni ni pwi

1SG.SBJ NEG cook-REF.OBJ fish NEG

'I didn't cook the fish.'

(Elicitation-2012-07-14-AD_BZ_CA_0015) 
It is possible to express a negative irrealis meaning in Koro - for example to negate a future event - but this requires a raising construction in which modal verb nap 'can' takes the irrealis clause as its complement. This is illustrated in (49-50) below. In (49), the negated clause expresses a future event, while in (50) it expresses the consequent of a hypothetical conditional construction.

(49) Ta nap you ku tuweni ni pwi.

ta nap you k-u tuwe-ni ni pwi

NEG can 1SG.SBJ IRR-1SG cook-SPEC.OBJ fish NEG

'I won't cook the fish.'

(Elicitation-2012-07-14-AD_BZ_CA)

(50) Ha kopwem ki la, ta nap i ki me pelingan pwi.

ha kopwe-m $\mathrm{k}-\mathrm{i}$ la ta nap i $\mathrm{k}-\mathrm{i}$ me pelingan pwi

PROSP hand-2SG.POSS IRR-3SG go NEG can 3SG IRR-3SG come up NEG

'If you put your hands (on it), it won't come up.'

(2011-04-23-AA-03_0239)

It is clear from these examples that negation is not an irrealis category in Koro. It does not trigger irrealis marking, and the realis-irrealis distinction is maintained under the scope of negation.

Another context in which irrealis marking is found in a number of languages is contexts of uncertainty or inference. As shown in (51), even when a speaker has a low level of confidence in the truth of a proposition, realis marking is still perfectly acceptable. Here the speaker does not know whether the subject hit his wife or not, but the subordinate proposition $i$ rei nambrulun 'he hit his wife' is nonetheless marked as realis. Likewise, in (52), occurrence of the adverb kapwa indicates that the speaker is uncertain about the truth of the proposition, but this does not trigger irrealis marking.

(51) Pwi, you ta lisi i rei nambrulun pwi.

pwi you ta lisi i $\emptyset$ re-i nambrulu-n pwi

NEG 1SG.SBJ NEG see 3SG REAL strike-SPEC.OBJ spouse-3SG.POSS NEG

'No, I didn't see him hit his wife.'

(Elicitation-2013-08-09-AD_CA_0143)

(52) Kapwa i chapol yesi window a i kini yau.

kapwa i $\emptyset$ chapol ye-si window=a i k-i-ni yau maybe 3SG REAL jump go-via window=DIST 3SG PERF-3SG-PERF leave:PERF

'Maybe he jumped through the window and is gone.' (2011-03-22-AH_AV-02_0036)

Similarly, inferential use of modal mas 'must', as in (53), does not trigger irrealis marking (compare this with its deontic use in (24) above, which does require irrealis marking).

(53) I mas i kini ndrah ndwal.

i $\emptyset$ mas i k-i-ni ndrah ndwal

3SG REAL must 3SG PERF-3SG-PERF board canoe

'He must have boarded the canoe.'

(Elicitation-2012-08-08-BZ_0057) 
Another context that surprisingly does not trigger irrealis marking is frustrative adverb tahit. This morpheme indicates that the event of the predicate was attempted, but not fully realized. For example, the utterance in (54) indicates that the subject tried to climb the tree, but did not make it to the top, and the utterance in (55) likewise entails that a spearing event took place, but that the intended object of the spearing was not struck. In neither case does the clause require irrealis marking.

(54) I nak kei a tahit.

i $\emptyset$ nak kei=a tahit

3SG REAL climb tree=DIST FRUSTR

'S/he tried to climb that tree (unsuccessfully).'

(Elicitation-2012-07-23-BZ_0054)

(55) You le soi i tahit.

you $\emptyset$ le so-i $\quad$ i tahit

1SG.SBJ REAL go.to spear-SPEC.OBJ 3SG FRUSTR

'I went and tried to spear him/her (unsuccessfully).' (Elicitation-2012-07-23-BZ_0061)

The final context in which irrealis marking might be expected is in interrogatives. In Koro, neither polar nor $w h$-interrogatives trigger irrealis marking. In (56), for example, a $w h$-question is unmarked for irrealis, while (57) shows an unmarked polar question.

(56) Mweh e mesi ndihe?

mweh=e $\emptyset$ me-si ndihe?

dog=PROX REAL come-via where

'Where did this dog come from?'

(v2012-08-02-CB-04_0077)

(57) Au hurong komu atua ne pwi?

au $\emptyset$ hurong komu atua ne pwi?

2SG REAL hear talk 1SG.POSS or NEG

'Did you hear what I said, or not?'

(2011-03-15-AH_AV-01_0183)

Both polar and content interrogatives can be marked for irrealis if this category is independently triggered, for example by future temporal reference, but interrogative mood does not in itself trigger irrealis marking.

\section{Discussion}

As discussed in $\S 1.2$, Bybee claims that languages such as Koro, where a single form is used in a wide variety of irrealis contexts, do not in fact have a coherent grammaticalized irrealis category. In contrast, she claims that what appears to be a single morpheme in such languages is in fact two or more polysemous morphemes, each having grammaticalized in its current construction from some common source morpheme. The Koro data, however, provide strong evidence that in this language the irrealis does constitute a single morpheme with an invariant, albeit abstract, meaning across uses. 
Let us first consider the formal data. Polysemous morphemes often exhibit divergent phonological or morpho-syntactic behavior. Take the polysemous have in English, mentioned earlier. In its obligation use it takes an infinitival complement, and often has a devoiced final consonant, whereas in its perfect aspect usage it takes a participial complement, and is often reduced to just the final consonant/v/. In contrast, Koro $k$ - has consistent phonological form and morpho-syntactic characteristics across all of its uses. Morphologically, the pattern of inflection is the same across all uses. Verbs in Koro do not inflect, and this inflectional paradigm is restricted to irrealis, perfect, and proximative aspect-mood heads. Likewise, the suppletive second person singular form $a$ occurs in all uses. Syntactically, the restriction against co-occurrence with negation holds across all uses. This is particularly telling since there is no semantic reason for this restriction, and in all its functions the irrealis can occur in the periphrastic negation construction with raising verb nap 'can'. It is also noteworthy that $k$ - occurs in exactly the same syntactic environment in all of its uses - unlike English have, it does not take different types of complement depending on which type of irrealis meaning it expresses. Lastly, as illustrated amply above, most of the uses of irrealis do not require any additional morpheme to specify the particular type of irrealis meaning. Indeed, a number of contexts do not allow any additional specifying morpheme to occur. This must be taken as evidence that the irrealis meaning expressed in each construction is contributed by the irrealis morpheme itself.

Further, this analysis seems to hold true for the whole Admiralties family. A cognate form with the same patterns of inflection and suppletion, and with roughly the same range of uses, is found in each of the other Admiralties languages for which sufficient data is available. ${ }^{5}$ This suggests that the current form and function of the irrealis have persevered for some time in the sub-group, and that this is not simply a recent idiosyncratic grammaticalization in Koro.

Turning now to semantics, we can note that a comparison of tables 1 and 4 above reveals that the Koro irrealis occurs in just those contexts predicted for a marker of temporal non-specificity. Namely, it occurs with future and prospective aspect, jussive modalities, conditional clauses, and past habitual aspect. Crucially, it is not triggered by negation, presupposition, uncertainty, or interrogative mood. These latter contexts are predicted to trigger irrealis marking for the 'unrealized' or 'non-assertion' types of irrealis, and they are reported to do so in a number of languages. The fact that Koro irrealis does not occur in these contexts suggests that neither of those characterizations captures its core meaning. I suggest, therefore, that the Koro irrealis encodes a meaning of 'temporal non-specificity'.

The question remains, however, as to what exactly 'temporal non-specificity' is. It has been observed that what is common to all the uses of an irrealis like that in Koro is that no specific event is referred to. In the case of future or hypothetical events, they cannot be referred to because they do not exist, while in the case of past habituals, a set of iterated events is evoked, but no single instance is referred to directly. The meaning of temporal non-specificity therefore has nothing to do with how precisely an event is located in time (for example with a temporal adverbial such as 'yesterday at 3:15 in the morning'), but has to do instead with whether the predicate refers to an instance of that event in the real world of the discourse. (I use the term 'real world of the discourse' to distinguish this from any possible worlds evoked, for example, by conditionals or deontic modals.) Baker and Travis (1997) provide a formal analysis of this notion of temporal non-specificity for

\footnotetext{
${ }^{5}$ These are Paluai (Dineke Schokkin, p.c.), Lele (Juliane Böttger, p.c.), Loniu (Hamel 1994), Sivisa Titan (Bowern 2011), and Kele (Ross 2002).
} 
Mohawk 'future' prefix $v$-, which has a very similar range of functions to those of irrealis in Koro. Most importantly, like the Koro irrealis, the Mohawk so-called 'future' occurs in past habitual contexts. Borrowing Heim's concept of Quantifier Indexing from the nominal domain, Baker and Travis argue that this morpheme in Mohawk indicates that the event variable of the verb undergoes Quantifier Indexing, and thus gets its quantificational force from the environment, rather than having its own inherent quantificational force. Whether this particular formal implementation is the most useful remains to be seen, but the analogy between the nominal and verbal domains is an apt one - a verbal category like that in Koro and Mohawk does indeed have a similar nonreferential function to that of a non-specific indefinite morpheme in the noun phrase.

Finally, let us briefly compare Koro with Nanti, a language that has been argued to exhibit a prototypical reality status category, expressing a binary distinction between realized and unrealized events (Michael to appear). Table 5 compares the contexts of irrealis marking in the two languages. It can be seen from this table that the contexts that trigger irrealis marking in Koro and Nanti largely overlap. However, in past habitual clauses and under the scope of negation, the two languages pattern differently. Koro allows irrealis marking in past habitual clauses, but not under negation, while Nanti exhibits the opposite pattern. The question at issue is whether these are idiosyncratic differences, explicable only by reference to particular grammaticalization trajectories within each language, or whether the differences point to the existence of two internally-coherent semantic categories. Clearly, an examination of just two languages cannot settle this debate, but I argue that these data are consistent with an analysis that invokes two stable categories - 'unrealized' and 'temporally non-specific'. Where the two languages both use irrealis marking, these are contexts that are both unrealized and temporally non-specific. Where marking in the two languages differs, namely with past habitual and negation, these are contexts that have different values for realization and temporal specificity. Michael makes a strong case that the irrealis category in Nanti is in fact a cohesive grammatical category that marks unrealized events, and the data in the current paper likewise support an analysis of Koro irrealis as an internally consistent category expressing temporal non-specificity. It remains to be seen whether similar analyses can be invoked to account for the apparently idiosyncratic patterning of irrealis morphemes in other languages.

\begin{tabular}{|c|c|c|}
\hline Semantics & Triggers irrealis in Nanti & Triggers irrealis in Koro \\
\hline Future & Yes & Yes \\
Deontic modality & Yes & Yes \\
Conditionals & Yes & Yes \\
Prospective, purposive & Yes & Yes \\
Desiderative complement & Yes & Yes \\
Interrogatives & No & No \\
\hline Past habitual & No & Yes \\
Negation & Yes & No \\
\hline
\end{tabular}

Table 5: Comparison of contexts that trigger irrealis marking in Koro (irrealis = temporally nonspecific) and Nanti (irrealis = unrealized) 


\section{Conclusion}

I have shown in this paper that Koro 'irrealis' morpheme $k$ - occurs in a wide variety of environments, not all of which can be understood as expressing 'unrealized' events. I argue that this is because the category 'irrealis' in Koro instead has a core meaning of temporal non-specificity. In contrast to Bybee's analysis of similar languages, I argue that the irrealis morpheme in Koro is a single morpheme with an invariant meaning across uses, and that it cannot be divided up into a number of polysemous morphemes with more specific meanings. When viewed in combination with a language such as Nanti, the Koro data suggest that there exist two distinct but stable notional domains that have been labeled 'irrealis' cross-linguistically — 'unrealized' and 'temporally non-specific'. Future cross-linguistic research on the domain of reality status should treat these semantic categories separately, in the hopes of determining whether they are in fact valid cross-linguistically.

\section{References}

BAKER, MARK and Lisa TraVis. 1997. Mood as Verbal Definiteness in a "Tenseless" Language. Natural Language Semantics 5:213-269.

Bowern, Claire. 2011. Sivisa Titan: Sketch Grammar, Texts, Vocabulary Based on Material Collected by P. Josef Meier and Po Minis. Hawaii: Oceanic Linguistics.

BybeE, JoAn. 1998. "Irrealis" as a Grammatical Category. Anthropological Linguistics 40:257271.

Callaghan, Catherine. 1998. Lake Miwok Irrealis. Anthropological Linguistics 40:228-233.

Chafe, Wallace. 1995. The Realis-Irrealis Distinction in Caddo, the Northern Iroquoian Languages, and English. In Joan Bybee and Suzanne Fleischman, eds., Modality in Grammar and Discourse, pp.349-365. Amsterdam: John Benjamins.

Comrie, Bernard. 1985. Tense. Cambridge: Cambridge University Press.

DE HAAn, FerdinAnd. 2012. Irrealis: Fact or Fiction? Language Sciences 32: 107-130.

FLECK, DAVID. 2007. Evidentiality and Double Tense in Matses. Language 83(3):589-614.

Givón, Talmy. 2001. Syntax: An Introduction. Amsterdam, Philadelphia: John Benjamins.

Hamel, Patricia. 1993. A Grammar and Lexicon of Loniu, Papua New Guinea. Canberra: Pacific Linguistics.

HEINE, BERnd. 2002. On the Role of Context in Grammaticalization. In IlseWischer and Gabriele Diewald, eds., New Reflections on Grammaticalization, pp. 83-101. Amsterdam: John Benjamins.

HEPNER, MARK. 2006. Bargam Grammar Sketch. S.I.L.

Michael, LEV. To appear. The Nanti Reality Status System: Implications for the Typological Validity of the Realis/Irrealis Contrast. Linguistic Typology.

Mithun, Marianne. 1999. The Languages of Native North America. New York: Cambridge University Press.

Palmer, F.R. 2001. Mood and Modality. Cambridge: Cambridge University Press.

Ross, Malcolm. 2002. Kele. In Malcolm Ross, John Lynch and Terry Crowley, eds., The Oceanic Languages, pp. 123-147. London, New York: Routledge. 
San Roque, lila, Alan Rumsey, Lauren Gawne, Stef Spronck, Darja Hoenigman, Alice Carroll, Julia Colleen Miller and Nicholas Evans. 2012. Getting the Story Straight: Language Fieldwork Using a Narrative Problem-Solving Task. Language Documentation and Conservation 6:165-17.

Timberlake, Alan. 2007. Aspect, Tense, Mood. In Timothy Shopen, ed., Language Typology and Syntactic Description, Volume III: Grammatical Categories and the Lexicon, pp. 280333. Cambridge: Cambridge University Press. 